\title{
PENINGKATAN PRODUKTIVITAS KERJA GURU MELALUI PENGEMBANGAN KEPEMIMPINAN TRANSFORMASIONAL DAN BUDAYA ORGANISASI
}

\author{
Atiyatu Jakiyah ${ }^{1}$, Sumardi ${ }^{2}$, Rais Hidayat ${ }^{2}$ \\ ${ }^{1}$ Guru SMK Al-Asiyah Cibinong, Bogor, Jawa Barat \\ ${ }^{2}$ Program Pascasarjana Universitas Pakuan, \\ Email: pasca@unpak.ac.id
}

\begin{abstract}
This research applies quantitative research with correlational approach. This study outlines how the productivity of teachers work can be improved, by researching and seeking relationships between: 1) transformational leadership of principals with teacher work productivity, 2) organizational culture with teacher work productivity, 3) transformational leadership and organizational culture together equal to teacher work productivity. This research was conducted at private vocational school in Cibinong Sub-district, Bogor Regency in Year 2018. The number of population in this study is 240 with the number of samples of 150. Data were collected from a questionnaire with Rating Scale. The analysis technique uses partial regression and multiple correlation. The research finding points out three conclusions that is: first, there is positive and significant correlation between transformational leadership with teacher work productivity. Second, there is a positive and significant correlation between organizational culture with teacher work productivity. Third, There is a positive and significant relationship between transformational leadership and organizational culture together with teacher work productivity.
\end{abstract}

Keywords: Transformational Leadership, Organizational Culture, Teacher Productivity

\begin{abstract}
ABSTRAK
Penelitian ini bertujuan untuk mengetahui bagaimana produktivitas kerja guru dapat ditingkatkan, dengan cara meneliti dan mencari hubungan antara: 1) kepemimpinan transformasional kepala sekolah dengan produktivitas kerja guru, 2) budaya organisasi dengan produktivitas kerja guru, 3) kepemimpinan transformasional dan budaya organisasi secara bersama-sama dengan produktivitas kerja guru. Penelitian ini menggunakan metode kuantitatif dengan pendekatan korelasional yang dilaksanakan di SMK Swasta di Kecamatan Cibinong Kabupaten Bogor Pada Tahun 2018. Populasi pada penelitian ini berjumlah 240 orang dengan jumlah sampel sebanyak 150 orang. Pengumpulan data untuk setiap variabel yang diteliti menggunakan angket dengan skala (Rating Scale). Teknik analisis menggunakan korelasi regresi parsial dan korelasi ganda. Hasil penelitian menghasilkan tiga kesimpulan yaitu : pertama, terdapat hubungan positif dan signifikan antara kepemimpinan transformasional dengan produktivitas kerja guru. Kedua, terdapat hubungan positif dan signifikan antara budaya organisasi dengan produktivitas kerja guru, Ketiga, Terdapat hubungan positif dan signifikan antara kepemimpinan transformasional dan budaya organisasi secara bersama-sama dengan produktivitas kerja guru.
\end{abstract}

Kata kunci: Kepemimpinan Transformasional, Budaya Organisasi, Produktivitas Guru 


\section{PENDAHULUAN}

Produktivitas kerja dalam suatu sekolah, baik sekolah negri maupun sekolah swasta hingga saat ini masih merupakan masalah yang aktual untuk dikaji dan diteliti. Produktivitas kerja selalu diarahkan pada bagaimana melakukan atau memanfaatkan sesuatu agar mencerminkan prinsip efektifitas dan efesiensi. Sesuatu dikatakan efektif apabila pemanfaatan berbagai aspek benar-benar tepat sasaran sesuai dengan tujuan yang diinginkan dan dikatakan efisien jika apa yang dilakukan mempertimbangkan aspek biaya, sarana prasarana, sumber daya (manusia dan material), dan waktu sehemat mungkin.

Mengingat pentingnya produktivitas kerja guru dalam mewujudkan kualitas pendidikan dan pembelajaran di sekolah, maka perlu dilakukan upaya perbaikan dan peningkatan mutu pendidikan agar tujuan pendidikan dapat terwujud yakni mencerdaskan kehidupan bangsa dan untuk menghasilkan kualitas sumber daya manusia yang berkualitas baik.

Berdasarkan dari pemikiran diatas perlu dilakukan penelitian untuk mengungkapkan bagimana cara meningkatkan produktivitas kerja guru sebagai variabel utama yang tentunya dihubungkan dengan variabel lain yang diduga dapat memiliki korelasi dengan produktivitas kerja guru yaitu kepemimpinan transformasional kepala sekolah dan budaya organisasi.

\section{Produktivitas Kerja Guru}

Wayne (2013:21) produktivitas adalah ukuran output barang dan jasa relatif terhadap masukan dari tenaga kerja, modal dan peralatan. Shamaki dalam Journal of education and practice (2015:201) produktivitas berkaitan dengan tanda pertumbuhan dan perkembangan suatu bangsa di seluruh dunia dan cara yang efektif dan efisien, rasio ukuran hal-hal yang dilakukan disekolah. Produktivitas guru dapat diukur dalam hal kinerja guru.

Schermerhorn (2011:465) produktivitas adalah efisiensi yang merubah masukan menjadi keluaran. Produktivitas sama dengan keluaran (output) di bagi masukan (input). Trivedi (2013:634) produktivitas merupakan sebuah sistem yang dipakai untuk mengumpulkan ukuran kinerja, kualitas hidup, dan fungsi belajar keluar.

Berdasarkan kajian teori tersebut, maka dapat disintesiskan bahwa hakikat produktivitas kerja guru adalah seluruh pencapaian hasil kerja guru selama satu tahun di lingkungan kerja dengan mengembangkan kreativitas dalam proses pembelajaran, efektif dan efisien dalam menggunakan waktu, biaya, sarana serta bertanggung jawab agar tercapainya tujuan pendidikan dengan menghasilkan sumber daya manusia yang berkualitas baik.

\section{Kepemimpinan Transformasional}

Colquitt, Lepine, Wesson (2009:428) kepemimpinan transformasional adalah kepemimpinan yang memberikan inspirasi kepada pengikut untuk berkomitmen terhadap visi bersama yang bermakna untuk pekerjaan mereka, disamping itu juga melayani berperan sebagai model yang membantu pengikut mengembangkan potensi dan pandangan mereka sendiri dan melihat masalah dari perspektif baru.

Kinicki and Fugate (2016:462) kepemimpinan transformasional adalah kepemimpinan yang merubah pengikiut untuk mencapai tujuan organisasi atas kepentingan diri sendiri. James dan Ogbonna (2013:356) dalam journal nya menyatakan bahwa Kepemimpinan transformasional meningkatkan motivasi, moral, dan kinerja pengikut melalui berbagai mekanisme. Gibson (2012:356) kepemimpinan transformasional adalah pemimpin yang memotivasi pengikutnya untuk bekerja mencapai tujuan organisasi sebagai kebanggaan dan aktualisasi diri. Robin dan Timoty (2013:383) mengemukakan bahwa kepemimpinan transformasional adalah pemimpin yang menginspirasi pengikutnya untuk lebih baik pada organisasinya dan memberikan dorongan yang luar biasa terhadap pengikutnya. Robins dan Timoty menambahkan penjelasannya bahwa kepemimpinan Transformasional kepala sekolah lebih efektif, karena lebih kreatif tetapi di dukung juga dengan semangat yang lebih aktif. 
Achua (2010:304) kepemimpinan transformasional adalah kepemimpinan yang berfungsi untuk mengubah status quo dengan mengartikulasikan visi kepada para pengikutnya masalah dalam sistem saat ini dan visi yang kuat tentang apa yang bisa dilakukan oleh sebuah organisasi baru. Yukl (2010: 277) kepemimpinan transformasional adalah pemimpin yang diikuti oleh pengikut yang loyal dan respek terhadap pemimpinnya dan mereka akan termotivasi untuk mengerjakan pekerjaan yang lebih baik lagi.Luthan (2011: 430) kepemimpinan transformasional adalah pemimpin yang memiliki karakteristik, pemimpin yang ideal, pemimpin yang memberi inspirasi dan kecerdasannya memikat dan menggambarkan pribadi yang penuh pertimbangan.

Berdasarkan kajian teoritik yang telah diuraikan di atas dapat disintesiskan bahwa kepemimpinan transformasional kepala sekolah adalah perilaku kepala sekolah dalam memberikan pengaruh, inspirasi, memahami bawahan, mengartikulasi visi untuk membuat perubahan, memberikan tanggung jawab yang lebih besar untuk mencapai tujuan sekolah.

\section{Budaya Organisasi}

Schermerhorn (2013:296) budaya organisasi adalah sistem kepercayaan dan nilai bersama yang memandu prilaku dalam organisasi. Menurut Hollenbeck (2010:283) Budaya organisasi merupakan cara informal untuk memahami kehidupan dan keanggotaan dalam organisasi yang mengikat bersama anggotanya serta mempengaruhi apa yang mereka pikirkan tentang diri mereka dan pekerjaan mereka. Ivancevich, et.al (2007:44) mengungkapkan bahwa budaya organisasi adalah apa yang dipersepsikan karyawan dan cara persepsi itu menciptakan suatu pola keyakinan, nilai dan ekspektasi.

Menurut McShane dan Von Glinow (2018: 388) Budaya organisasi merupakan suatu nilai dan asumsi yang dimiliki bersama sebuah organisasi dan berkaitan dengan apa yang penting dan tidak penting bagi organisasi serta mengarahkan semua anggota organisasi untuk tercapainya tujuan organisasi. Budaya organisasi tidak dapat terlihat dengan mata terlanjang namun merupakan template yang kuat yang membentuk apa yang terjadi di tempat kerja. Menurut McShane dan Von Glinow (2018: 388) elemen budaya organisasi terdiri dari: 1) Artefak, 2) Nilai, Keyakinan dan evaluasi apa yang baik atau buruk, benar atau salah, 3) Asumsi bersama.

Menurut Luthans (2007:125) budaya organisasi memiliki beberapa karakteristik penting, yaitu (1) aturan perilaku yang diamati; (2) norma; (3) nilai dominan; (4) filosofi; (4) aturan; (5) iklim organisasi). George and Jones (2012:502) budaya organisasi adalah seperangkat nilai, kepercayaan, dan norma bersama yang mempengaruhi keberaturan dalam bertindak, karyawan berpikir, merasa, dan berperilaku satu sama lain dan terhadap orangorang di luar organisasi.

Berdasarkan uraian yang telah dikemukakan di atas, maka dapat disintesiskan bahwa budaya organisasi adalah pemaknaan individu terhadap nilai, norma, peraturan, yang berlaku dan disepakati dalam sebuah organisasi yang dapat mengarahkan persepsi, pandangan hidup dan keberaturan cara bertindak para anggotanya untuk mencapai tujuan organisasi.

\section{METODE PENELITIAN}

Penelitian ini adalah penelitian kuantitatif dengan pendekatan korelasional yang terdiri atas dua variabel bebas, yaitu kepemimpinan transformasional kepala sekolah $\left(\mathrm{X}_{1}\right)$ dan Budaya organissi $\left(\mathrm{X}_{2}\right)$, serta satu variabel terikat yaitu produktivitas kerja guru (Y).

Penelitian ini bertujuan untuk mengetahui bagaimana produktivitas kerja guru dapat ditingkatkan, dengan cara meneliti dan mencari hubungan antara: 1) kepemimpinan transformasional kepala sekolah dengan produktivitas kerja guru, 2) budaya organisasi dengan produktivitas kerja guru, 3) kepemimpinan transformasional dan budaya organisasi 
secara bersama-sama dengan produktivitas kerja guru. Penelitian ini dilaksanakan di SMK Swasta yang berada di Kecamatan Cibinong Kabupaten Bogor Pada Tahun 2018. Populasi pada penelitian ini berjumlah 240 orang dengan jumlah sampel sebanyak 150 orang. Pengumpulan data untuk setiap variabel yang diteliti menggunakan angket dengan skala (Rating Scale). Teknik analisis menggunakan korelasi regresi parsial dan korelasi ganda.

\section{HASIL PENELITIAN}

\section{Pengujian Persyaratan Analisis}

\section{Uji Normalitas}

Hasil perhitungan uji normalitas galat baku taksiran $\left(\mathrm{Y}-\hat{\mathrm{Y}}_{1}\right)$ variabel produktivitas kerja guru $(\mathrm{Y})$ atas variabel kepemimpinan transformasional $\left(\mathrm{X}_{1}\right)$ diperoleh nilai $\mathrm{L}_{\text {hitung }}=0,06$ sedangkan nilai $\mathrm{L}_{\text {tabel }}=0,07$. Persyaratan normal adalah $\mathrm{L}_{\text {hitung }}<\mathrm{L}_{\text {tabel }}$, dengan demikian galat baku taksiran $\left(\mathrm{Y}-\hat{\mathrm{Y}}_{1}\right)$ variabel produktivitas kerja guru $(\mathrm{Y})$ atas variabel kepemimpinan transformasional $\left(\mathrm{X}_{1}\right)$ berasal dari populasi yang berdistribusi normal.

Hasil perhitungan uji normalitas galat baku taksiran $\left(\mathrm{Y}-\hat{\mathrm{Y}}_{1}\right)$ variabel produktivitas kerja guru $(\mathrm{Y})$ atas variabel budaya organisasi $\left(\mathrm{X}_{2}\right)$ diperoleh nilai $\mathrm{L}_{\text {hitung }}=0,05$ sedangkan nilai $\mathrm{L}_{\text {tabel }}=0,07$. Persyaratan normal adalah $\mathrm{L}_{\text {hitung }}<\mathrm{L}_{\text {tabel }}$, dengan demikian galat baku taksiran $\left(\mathrm{Y}-\hat{\mathrm{Y}}_{1}\right)$ variabel produktivitas kerja guru $(\mathrm{Y})$ atas variabel budaya organisasi $\left(\mathrm{X}_{2}\right)$ berasal dari populasi yang berdistribusi normal.

\section{Uji Homogenitas}

Pengujian homogenitas dilakukan dengan menggunakan uji Bartlett. Berdasarkan hasil pengujian diperoleh nilai $\chi^{2}$ hitung $=83,22$ sedangkan $\chi^{2}$ tabel $=124,342$. Persyaratan data tersebut homogen bila $\chi^{2}$ hitung $<\chi^{2}$ tabel. Hal tersebut bermakna bahwa kelompok data produktivitas kerja guru $(\mathrm{Y})$ atas kepemimpinan transformasional $\left(\mathrm{X}_{1}\right)$ berasal dari populasi yang homogen.

Pengujian homogenitas varians data produktivitas kerja guru atas budaya organisasi dilakukan dengan menggunakan uji Bartlett. Berdasarkan hasil pengujian diperoleh nilai $\chi^{2}$ hitung $=55,12$ sedangkan $\chi_{\text {tabel }}^{2}=124,342$. Persyaratan data tersebut homogen bila $\chi^{2}$ hitung $<$ $\chi^{2}$ tabel. Hal tersebut bermakna bahwa kelompok data produktivitas kerja guru (Y) atas budaya organisasi $\left(\mathrm{X}_{2}\right)$ berasal dari populasi yang homogen.

\section{Pengujian Hipotesis}

\section{Hubungan antara variabel Kepemimpinan Transformasional dengan Produktivitas Kerja Guru}

Analisis linier sederhana antara kepemimpinan transformasional dengan produktivitas kerja guru memiliki persamaan regresi $\hat{\mathrm{Y}}=9,51+0,98 \mathrm{X}_{1}$ dengan arah koefisien regresi sebesar 0,98 dan konstanta sebesar 9,51. Pengujian mengenai kebenaran hasil regresi tersebut, juga dimaksudkan untuk menguji hipotesis tentang adanya hubungan positif antara kepemimpinan transformasional $\left(\mathrm{X}_{1}\right)$ dengan produktivitas kerja guru (Y), maka untuk keperluan itu diperlukan uji signifikasi dan linier terhadap persamaan regresi dengan menggunakan SPSS 23.

Kekuatan hubungan antara variabel kepemimpinan transformasional dan produktivitas kerja guru ditunjukkan oleh koefisien determinasi $\left(\mathrm{r}^{2}\right)$ sebesar 0,919 . Artinya kontribusi kepemimpinan transformasional pada produktivitas kerja guru sebesar 91,9\% sementara 8,1\% sisanya merupakan kontribusi faktor lain 


\section{Hubungan variabel Budaya Organisasi dengan Produktivitas Kerja Guru}

Hipotesis kedua dalam penelitian ini adalah terdapat hubungan positif antara budaya organisasi $\left(\mathrm{X}_{2}\right)$ dengan produktivitas kerja guru $(\mathrm{Y})$. Analisis linier sederhana antara budaya organisasi dengan produktivitas kerja guru memiliki persamaan regresi $\hat{Y}=9,28+1,03 X_{2}$ dengan arah koefisien regresi sebesar 1,03 dan konstanta sebesar 9,28.

Kekuatan hubungan antara variabel budaya organisasi dan produktivitas kerja guru ditunjukkan oleh koefisien determinasi $\left(\mathrm{r}^{2}\right)$ sebesarnya 0,926. Artinya kontribusi budaya organisasi pada pembentukan produktivitas kerja guru sebesar $92,6 \%$ sementara 7,4\% sisanya merupakan kontribusi faktor lain.

\section{Hubungan antara Kepemimpinan Transformasional $\left(\mathrm{X}_{1}\right)$ dan Budaya Organisasi Sekolah $\left(\mathrm{X}_{2}\right)$ secara Bersama-sama dengan Produktivitas Kerja Guru (Y)}

Analisis linier ganda antara kepemimpinan transformasional dan budaya organisasi secara bersama-sama dengan produktivitas kerja guru memiliki persamaan regresi $\hat{Y}=8,26+$ $0,38 \mathrm{X}_{1}+0,63 \mathrm{X}_{2}$ dengan arah koefisien regresi $\mathrm{a}_{1}$ sebesar $0,38, \mathrm{a}_{2}$ sebesar 0,63 dan konstanta sebesar 8,26.

Hasil menunjukkan nilai $\mathrm{F}=986,674(\mathrm{P}<0,01)$, maka persamaan regresi $\hat{\mathrm{Y}}=8,26+$ $0,38 \mathrm{X}_{1}+0,63 \mathrm{X}_{2}$. dinyatakan signifikan. Jadi $(\mathrm{P}<0,01)$ adalah signifikasi untuk persamaan regresi $\hat{Y}=8,26+0,38 X_{1}+0,63 X_{2}$. Kesimpulannya bahwa kepemimpinan transformasional dan budaya organisasi dapat digunakan untuk memprediksi produktivitas kerja guru.

Hasil menunjukkan nilai koefisien korelasi (r) sebesar 0,965 yang menunjukkan kekuatan hubungan antara kepemimpinan transformasional dan budaya organisasi secara bersama-sama dengan produktivitas kerja guru 0,965. Sedangkan nilai koefisien determinasi $\left(r^{2}\right)$ sebesar 0,931 menunjukkan kontribusi kepemimpinan transformasional dan budaya organisasi secara bersama-sama pada produktivitas kerja guru 93,1\% sementara 6,9\% sisanya merupakan kontribusi faktor lain.

\section{Uji Korelasi Parsial}

Berdasarkan hasil perhitungan diperoleh nilai korelasi parsial antara budaya organisasi dengan produktivitas kerja guru dikendalikan oleh kepemimpinan transformasional sebesar 0,383, nilai probabilitas (sig.) sebesar 0,00 yang berarti lebih kecil dari 0,01 sebagai syarat hubungan yang signifikan. Hal ini berarti hubungan antara budaya organisasi dengan produktivitas kerja guru tetap signifikan meskipun dikontrol oleh variabel kepemimpinan transformasional, dengan kata lain variabel kepemimpinan transformasional tidak mempengaruhi secara signifikan hubungan antara budaya organisasi dengan produktivitas kerja guru.

Berdasarkan hasil perhitungan diperoleh nilai korelasi parsial antara kepemimpinan transformasional dengan produktivitas kerja guru dikendalikan oleh budaya organisasi sebesar 0,257, nilai probabilitas (sig.) sebesar 0,00 yang berarti lebih kecil dari 0,01 sebagai syarat hubungan yang signifikan. Hal ini berarti hubungan antara kepemimpinan transformasional dengan produktivitas kerja guru tetap signifikan meskipun dikontrol oleh variabel budaya organisasi, dengan kata lain variabel budaya organisasi tidak mempengaruhi secara signifikan hubungan antara kepemimpinan transformasional dengan produktivitas kerja guru. 


\section{PEMBAHASAN}

\section{Hubungan Positif antara kepemimpinan transformasional dengan Produktivitas Kerja Guru}

Berdasarkan uji hipotesis didapatkan hasil koefisien korelasi $\mathrm{r}_{\mathrm{y} 1}=0,959$ dengan koefisien determinasi $\mathrm{r}_{\mathrm{y} 2}^{2}=0,919$ menunjukkan bahwa $91,9 \%$ produktivitas kerja guru dapat dihasilkan dari adanya variabel kepemimpinan transformasional. Hubungan fungsional antara kepemimpinan transformasional dengan produktivitas kerja guru memberikan arti bahwa semakin tinggi kepemimpinan transformasional diikuti dengan peningkatan produktivitas kerjanya semakin baik.

Hubungan fungsional antara budaya organisasi dengan produktivitas kerja guru ditunjukkan dengan persamaan regresi $\hat{Y}=9,51+0,98 X 1$. Hubungan antara kedua variabel ini adalah sangat signifikan dan linier, artinya apabila kepemimpinan transformasional ditingkatkan sebesar satu satuan maka produktivitas kerja guru diprediksi akan meningkat sebesar 0,98 satuan dengan konstanta sebesar 9,51. Hal ini memberikan arti bahwa semakin tinggi kepemimpinan transformasional maka produktivitas kerja guru akan menjadi semakin baik. Kepemimpinan tranformasional memberikan sumbangan positif bagi peningkatan produktivitas kerja guru.

Hasil penelitian tersebut sejalan dengan hasil penelitian Iraj Soltani, tahun 2014 melalui jurnalnya yang berjudul "Investigating the relationship between transformational leadership and employes' productivity in Shiraz Special Economic Zone".Journal of Novel Aplied Sciences.Volume 2-3: 181-184. Menyatakan terdapat hubungan positif yang signifikan antara kepemimpinan transformasional dan produktivitas. Selain itu, penelitian ini juga sependapat dengan James dan Ogbonna (2013:356) dalam journal nya menyatakan bahwa Kepemimpinan transformasional meningkatkan motivasi, moral, dan kinerja pengikut melalui berbagai mekanisme.

\section{Hubungan Positif antara Budaya Organisasi dengan Produktivitas Kerja Guru}

Berdasarkan uji hipotesis di dapatkan hasil koefisien korelasi $r_{\mathrm{y} 2}=0,962$ dengan koefisien determinasi $\mathrm{r}^{2}{ }_{\mathrm{y} 2}=0,926$, hal ini berarti bahwa variabel budaya organisasi memberikan kontribusi sebesar $92,6 \%$ terhadap produktivitas kerja guru. Hubungan fungsional antara budaya organisasi dengan produktivitas kerja guru ditunjukkan dengan persamaan regresi $\hat{Y}=9,28+1,03 X_{2}$.

Hubungan antara kedua variabel ini adalah sangat signifikan dan linier, artinya apabila budaya organisasi ditingkatkan sebesar satu satuan maka produktivitas kerja guru diprediksi akan meningkat sebesar 1,03 satuan dengan konstanta sebesar 9,28. Hal ini memberikan arti bahwa semakin tinggi budaya organisasi maka produktivitas kerja guru akan menjadi semakin baik. Budaya organisasi memberikan sumbangan positif bagi peningkatan produktivitas kerja guru.

Hasil penelitian tersebut sejalan dengan hasil penelitian Muhammad Mahdiyeh, 2016 dalam Jurnal yang berjudul “ Impact of Organizational Culture on Productivity: a study among employes of Ministry of Youth and Sports Iran”. International Journal of Humanities and Cultural Studies. ISSN 2356-5926, Volume 3;170-177. Menyatakan bahwa korelasi ini dapat dinilai secara tepat dalam model regresi. Hasil penelitian ini juga sejalan dengan pendapat Kinicki and fugate (2016:480) menyatakan bahwa budaya organisasi didefinisikan sebagai himpunan implisit bersama, diambil-untuk-diberikan asumsi yang dimiliki kelompok 
dan yang menentukan bagaimana persepsi, pemikiran, dan bereaksi terhadap berbagai lingkungannya.

\section{Hubungan positif antara Kepemimpinan Transformasional dan Budaya} Organisasi Sekolah secara Bersama-sama dengan Produktivitas Kerja Guru.

Berdasarkan uji hipotesis didapatka hasil koefisien korelasi sebesar $r_{\mathrm{y} .12}=0,965$ dan koefisien determinasi $r_{\text {y.12 }}^{2}=0,931$ sehingga dapat diartikan bahwa 93,1\% produktivitas kerja guru dapat dihasilkan melalui variabel kepemimpinan transformasional dan budaya organisasi secara bersama-sama.

Koefisien determinasi variabel budaya organisasi sebesar 92,6\% relatif lebih tinggi jika dibandingkan dengan koefisien determinasi variabel kepemimpinan transformasional yaitu sebesar $91,9 \%$. Perbedaan perolehan nilai koefisien determinasi antara kedua variabel secara sendiri-sendiri tersebut memberikan makna bahwa berdasarkan penilaian responden, faktor budaya organisasi guru ternyata memberikan sumbangan yang lebih positif dan signifikan bagi produktivitas kerja guru.

Hasil penelitian ini sejalan dengan pendapat Trivedi (2013:634) yang menyatakan bahwa produktivitas merupakan sebuah sistem yang dipakai untuk mengumpulkan ukuran kinerja, kualitas hidup, dan fungsi belajar keluar. Dari definisi di atas dapat dikatagorikan bahwa produktivitas merupakan sistem yang tidak terpisahkan dari kegiatan sehari-hari sehingga dapat menunjukkan kualitas hidup yang lebih baik sehingga produktivitas menjadi meningkat. Produktivitas kerja guru adalah seluruh pencapaian hasil kerja guru selama satu tahun dengan mengembangkan kreativitas dalam proses pembelajaran, efektif dan efisien dalam menggunakan waktu, biaya, sarana serta bertanggung jawab agar tercapainya tujuan pendidikan dengan menghasilkan sumber daya manusia yang berkualitas baik.

Selain itu untuk melihat seberapa besar kekuatan hubungan antara variabel bebas dan variabel terikat serta untuk mendapatkan solusi optimal dari penelitian ini, dapat dilihat pada gambar konstelasi penelitian dan statistik berdasarkan analisis model Scientific identification theory to conduct operation research in education management (SITOREM). Teori pengenalan ilmiah untuk riset operasi dibidang manajemen pendidikan untuk menentukan penurunan saran atau rekomendasi hasil penelitian (Hardhienata, 2017) seperti yang ditunjukkan pada gambar berikut: 


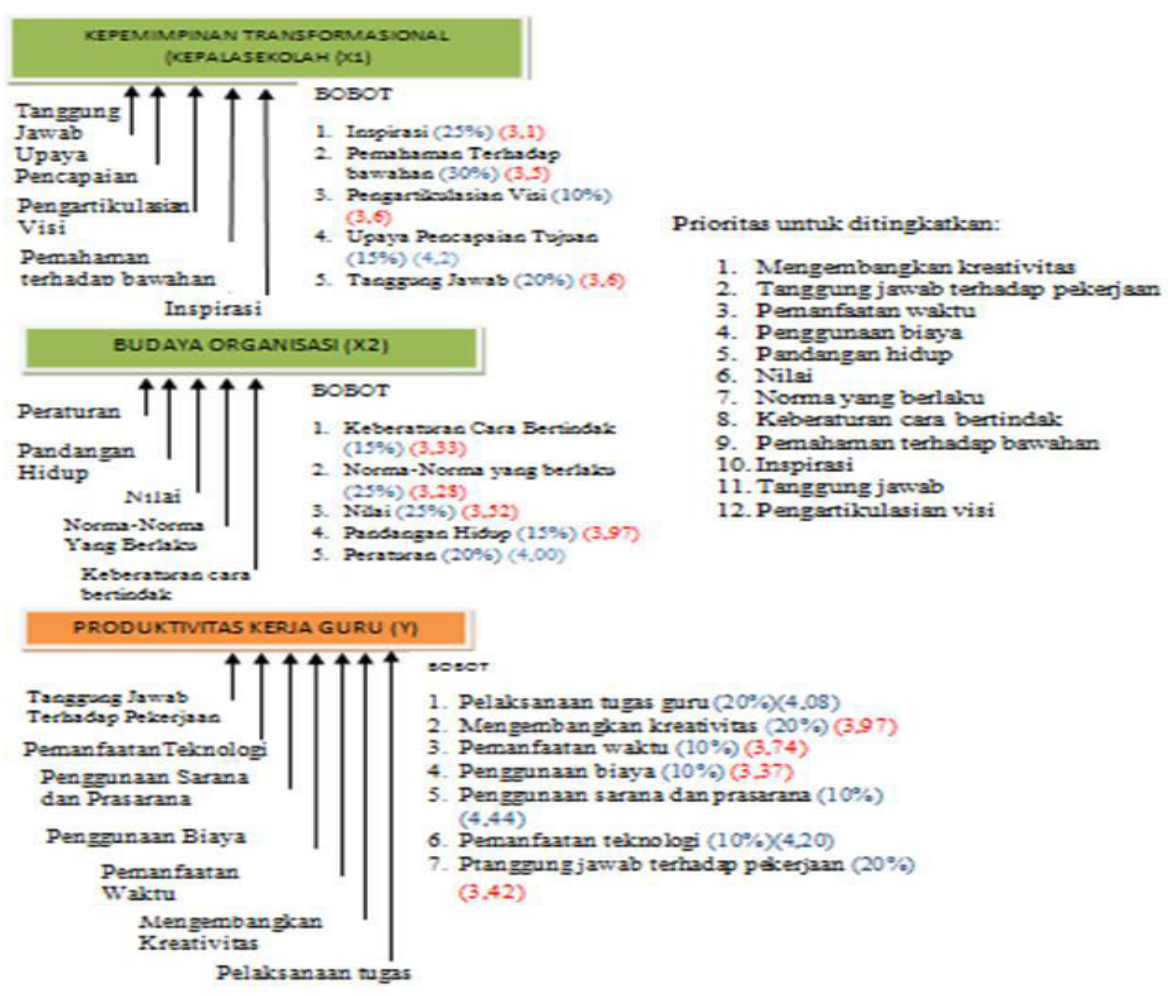

Gambar . Hasil akhir dari optimasi terhadap faktor-faktor dari masing-masing variabel

\section{SIMPULAN}

Berdasarkan analisis terhadap data hasil penelitian dapat disimpulkan terdapat hubungan positif sangat signifikan antara kepemimpinan transformasional kepala sekolah dengan produktivitas kerja guru, antara budaya organisasi dengan produktivitas kerja guru, antara kepemimpinan transformasional kepala sekolah dan budaya organisasi secara bersamasama dengan produkrivitas kerja guru. Berdasarkan hasil penelitian ini maka untuk meningkatkan produktivitas kerja guru dapat dilakukan dengan meningkatkan kepemimpinan transformasional kepala sekolah dan perbaikan pada budaya organisasi.

\section{DAFTAR PUSTAKA}

Achua, Christopher,F. 2010. Efective Leadership. South-Western: Cengage Learning International Offices.

Ahlgrim Richard Wayne. 2010. A Thorough and Efficient School Funding Student Achiepment And Productivity. Indian State University.

Cascio,Wayne,F. 2013. Managing Human Resources: Productivity,Quality of Work Life,Profits.New York: McGraw-Hill International Edition.

Colquitt Jasson A, Lepine Jeffery A,Wesson Michael J. 2009. Organization Behavior. New York: McGraw-Hill International Edition.

Emron Edison. 2016. Manajemen Sumber Daya Manusia: Strategi dan perubahan dalam rangka meningkatkan kinerja pegawai dan organisasi. Bandung: Alfabeta. 
George, Jenifer, M and Jones Gareth R. 2012. Understanding and Managing Organizational Behavior sixth edition, New York: Prentice Hall.

Gibson James L.et.al 2012. Organization Behavior, Structure, Processes. New York:McGraw Hill.

Hollenbeck John R. 2010. Organizational Behavior. New York: madison Ave

Iraj Saltoni. 2014. Investigating the relationship between transformational leadership and employes' productivity in Shiraz Special Economic Zone. Journal of Novel Aplied Sciences. Volume 2-3: 181-184.

Ivancevich, John M. et al. 2007. Perilaku dan Manajemen Organisasi Edisi ke Tujuh, Buku Terjemahan Gina Gania. Jakarta: Erlangga

Kinicki, Angelo,et al .2016. Organizational Behavior:A Practical, Problem Solving Approach. New York: MC Graw Hill.

Madhukar H. Trivedi. 2013. Increase in Work Productivity of Depressed Individuals With Improvement in Depressive Symptom Severity. Am J Psychiatry.

McShane,Steven L dan Von Glinow,Mary Ann. 2018, Organizational Behavior : Emerging Knowledge Global Reality, Eight Edition,New York: MC Graw Hill

Muhammad Mahdiyeh.2016. Impact of Organizational Culture on Productivity: a study among employes of Ministry of Youth and Sports Iran. . Volume 3: 170-177.

Schermerhorn,John,R. 2012. Organizational Behavior. United States of America:Quad Graphics.

Hardhienata. S. 2017. The Development Of ScientificIdentification Theory to Conduct Operation Research inEducation Management. IOP Conference Series: Materials Science anad Engineering. 